\title{
DESIGN AND MANUFACTURING OF TRANSMISSION SYSTEM FOR SELF-PROPELLED ONION HARVESTER
}

\author{
Shantanu Pawar \\ UG Student, Department of Mechanical Engineering ,Savitribai Phule Pune University, Pune, \\ Maharashtra, India. \\ Email-shantanupawar45@gmail.com
}

\begin{abstract}
ABSRACT meet them.

\section{INTRODUCTION}

The agricultural tractor is one of the class of mobile machines that involves the 'traction' process. The word 'traction' and name 'tractor' come from the word to 'draw' or 'pull' so A tractor is essentially a pulling machine; other mobile machines, such as locomotives, fall into the same category. Vehicles such as road trucks and even automobiles, which are essentially load-carrying vehicles, are also involved in the traction process.
\end{abstract}

Agricultural vehicles work under a variety of conditions and maximum work-rate and Minimum fuel consumption is dependent on selecting the correct engine speed, transmission ratio, and implement width and depth. Although the well-known technique of "gear up, throttle down" produces fuel savings, particularly at part load, a tractor with a fully integrated engine-transmission-implement control system would have a dynamic response to varying loads to achieve the maximum work-rate for the minimum fuel consumption under all conditions. This report considers transmissions that could be used on an integrated control tractor and discusses the transmission requirements and how well the various types

The tractor is also in the category of machines that operate in what are known as "off-road" conditions. Other machines in this class include earth moving, mining, and military equipment, as well as four-wheel drive motor vehicles for cross-country travel.

Design of agricultural tractor should include an understanding of the operator-machine interface, knowledge of human factors engineering, and integration of safety into the design.Human factors include things like riding comfort, visibility, control location and arrangement, control ease of use, thermal comfort design, and sound control. When these factors are properly incorporated in the design, the operator can perform complex tasks with efficiency, safety, and a minimum of fatigue.

Agricultural and other off-road tyres primarily have to satisfy different operational requirements, such as better traction performance, limit slip sinkage, limit soil compaction and support weight of the machine. These requirements strongly depend on the soil characteristics and tyre tread design. Little attention has been devoted to discrete element method (DEM) model that can be used to predict the traction performance as a function of tyre tread design with respect to to soil characteristics considering the effects of discontinuous behaviour of terrain during interaction. An early attempt to predict the tyre-soil interaction has been done by modelling terrain as a collection of deformable layer springs and tyre as deformable ring with tread geometry. Moreover, recently attempts in numerical and discrete element models have been studied and developed, these models can predict traction performance, stresses and sinkage of wheel, but have the weakness of predicting the effects of build-up and cleaning which rise due to discreteness deformation of terrain during interaction. Given the fact that, deformation of terrain is discontinuous in nature during interaction which rise to bulldozing effects, build-up and cleaning phenomenon and these mostly affects performance of wheel and off-road vehicles, then modelling terrain as assemblage of rigid colliding bodies must be studied and developed to predict those effects with respect to soil rheology.

The tire-soil interaction mechanism has a significant impact on off-road vehicle 
performance. Soft soil can drastically reduce tyre traction performance to the point where movement is impossible. In this study, a tire model able to predict the performance of rigid wheels and flexible tires is developed. For steady-state conditions, the model employs a semi-empirical approach and predicts basic characteristics such as drawbar pull and driving torque. and the lateral force, as well as complex behaviours, such as the slip-sinkage phenomenon and the multi-pass effect.

Vehicle model. Several tire geometries, vehicle configurations (FWD, RWD, AWD), soil types, and Terrain profiles are taken into account when evaluating performance under various simulation scenarios. The simulation environment represents an effective tool to realistically analyse the impact of tire parameters (size, inflation pressure) and torque distribution on the energy efficiency. It has been proven that larger tyres with lower inflation pressure provide better traction and energy efficiency (under steady-state working conditions). The torque distribution strategy between the axles has a significant impact on traction and efficiency: the two variables cannot be clearly maximised at the same time, and a trade-off must be found.

Models for predicting rolling resistance include wheel numeric and various versions of mobility numbers. In this study, data on the rolling resistance of cross ply and radial ply tyres were compared to the results of various models. The precision of models in predicting rolling resistance was also evaluated. The $\mathrm{F}$ test and the line method were used for this purpose. According to the evaluation results, the $\mathrm{Cn}$ and $\mathrm{Bn}$ models overestimated the rolling resistance for both cross ply and radial ply tyres, but the slope of these models did not differ significantly from lines. The results showed that if an adjusting coefficient could be used, these models could predict better.

\section{CORE CONTENT}

\subsection{Power transmission systems and outlets}

The transmission systems on the tractor serve to transmit power from the engine to the power outlets, viz: (i) Traction system (wheels / drawbar / three point linkage)

(ii) Power take off

(iii) Hydraulic (oil) supply

The transmission elements which comprise these systems, may be classified according to their principle of operation:

(i) Mechanical $=$ a. gears

b. belts/chains

(ii) Hydrostatic $=$ a. fluid pressure

(iii) Hydro-kinetic $=$ a. fluid momentum

-fluid coupling

-torque converter

The three transmission systems that transmit power to the three main outlets are discussed below.
(A) Traction transmission

(i) Conventional tractors

The components generally referred to as the 'transmission' and / or the 'gear box' transmit the rotation of the engine to the rear wheels as shown in Figure 1.1.In a traditional tractor, this is usually a mechanical system with shafts, gears, and so on.

Because the engine rotates at high speed (a few 1000 's of rpm) and the tractor wheels must operate at low speed (a few 10's of rpm), the traction transmission has the function of reducing the speed of rotation of the engine to that required for the rear wheels. Furthermore, because not all operations require the tractor to travel at the same speed, the transmission has the function of allowing the operator to vary the speed reduction from engine to wheels. Thus, the travel speed may change in from 6 to 12 steps, i.e., from about $1 \mathrm{~km} / \mathrm{hr}$ in a 'low' gear with a 'large' reduction ratio to about 20 $\mathrm{km} / \mathrm{hr}$ in a 'high' gear with a 'small' reduction ratio. The variable ratio is achieved by 'changing gears' (in mesh) so that the drive (motion) passes through gears of various sizes. This changes the overall ratio of the transmission, causing the wheels to run faster or slower. 


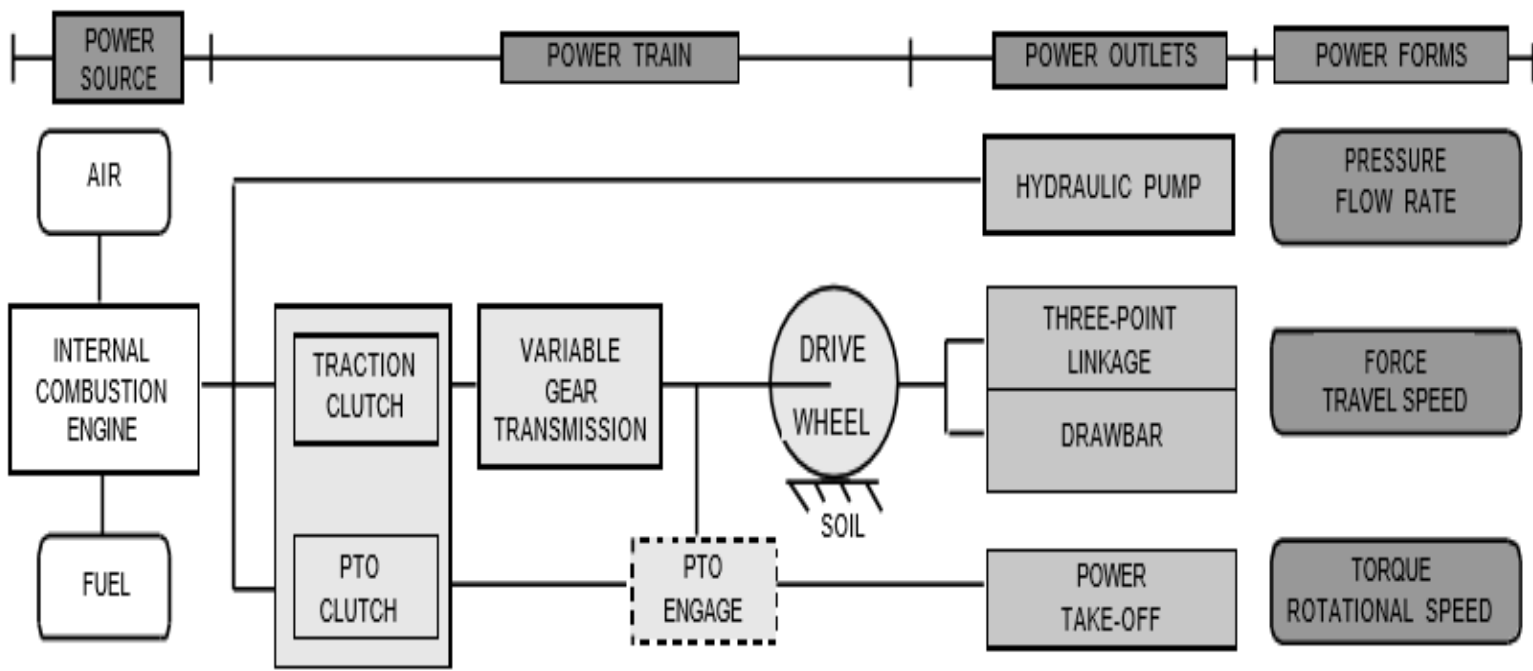

Figure 1: - Typical power trains for a conventional tractor

The (traction) clutch, which is usually frictional, is installed between the engine and the transmission. When power transmission is required and the tractor begins to move, the driver can temporarily disconnect the engine from the rest of the transmission and gradually reconnect it. Transmission clutches of this type typically consist of one or more friction surfaces connected to the engine and pressed by springs on either side of a disc connected to the rest of the transmission. When the pressure on the surfaces is removed (by disengaging the clutch with the pedal), the engine can continue to turn without turning the transmission or the wheels. The 'differential' part of the transmission divides the drive to the wheels and allows them to turn at different speeds as the tractor turns a corner. Both wheels continue to drive because their input torques remain equal, but they turn at different speeds, corresponding to the radii of the curves on which they are travelling. Many tractors have a device that allows the differential to be locked. This forces both rear wheels to turn at the same speed, allowing the tractor to be driven out of a situation in which the differential would normally allow one wheel to slip while the other would not rotate at all.With the lock engaged, the wheel speeds are now equal, but the torques are different; thus, turning a corner is no longer possible (or difficult).

The 'final drive,' which consists of speed reduction gears after the differential, is another common component in the transmission. These are placed near the wheels in this position to avoid the low speed / high torque in previous parts of the transmission..

\section{(ii) Walking tractor (Power tiller)}

The transmission in a two-wheel or walking tractor (Figure 1.3) is typically a variable speed $\mathrm{V}$-belt drive from the engine that also acts as a clutch as it is tightened or loosened. A small gearbox can then be installed, which drives the wheels via chains.

These tractors are not typically equipped with a power take-off, but they can be used to power equipment such as a pump while stationary. The belt drive to the wheels is removed and the attached equipment is driven directly.

Power losses in the mechanical transmission systems of tractors are usually small, probably less than $10 \%$. 


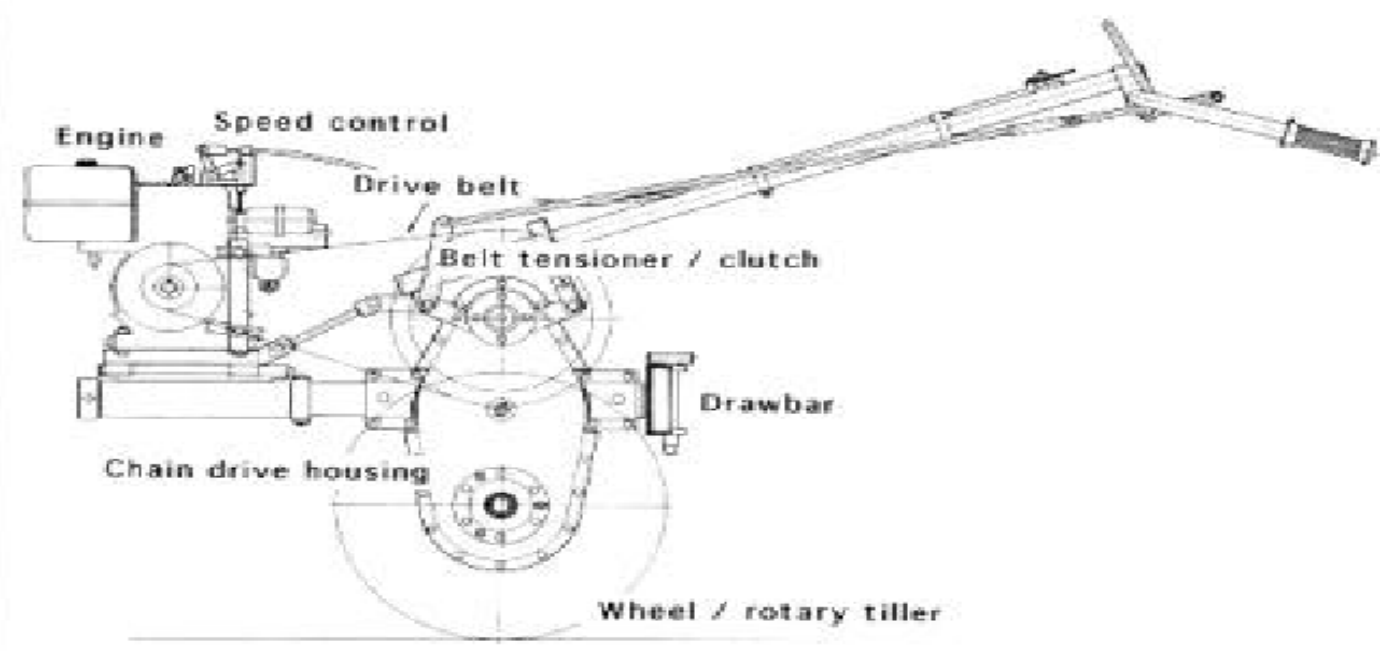

Figure 2: - Transmission system for walking tractor / power tiller

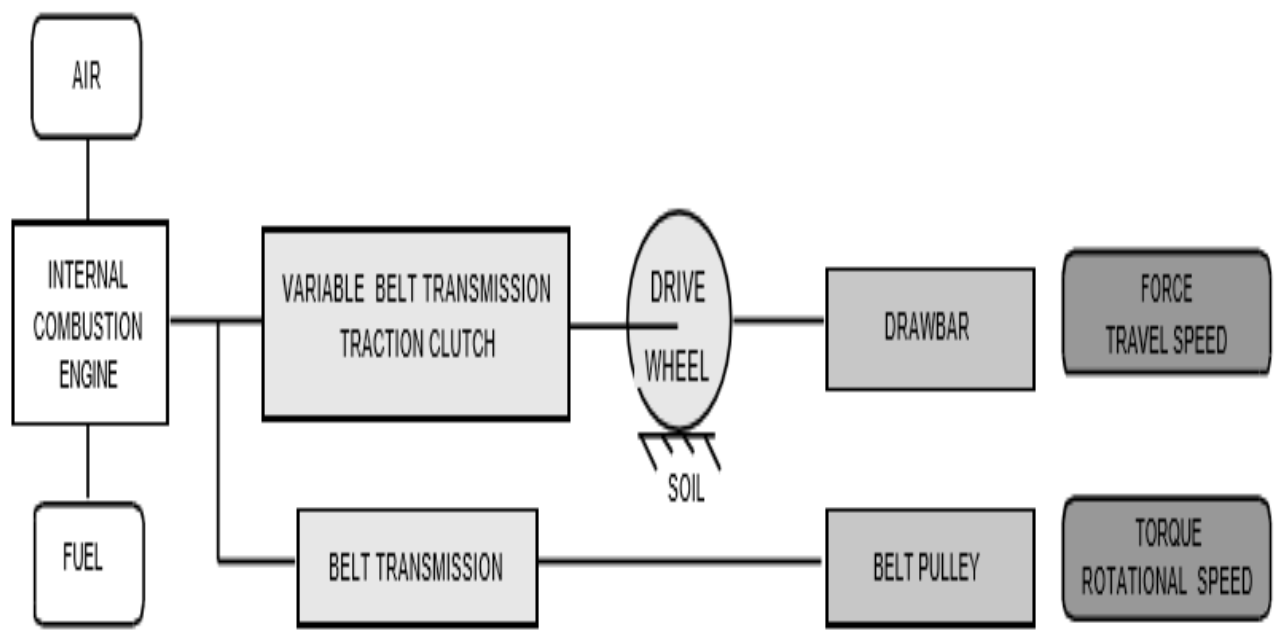

Figure 3: - Transmission system for walking tractor / power tiller 


\section{(b) Power take-off transmission}

An ('engine speed') power take-off (PTO) is a transmission from the engine to a shaft that passes to the outside of the tractor, usually at the rear, and can be engaged to drive attached machines (Figure 1.2). Power is transferred from the engine to the transmission clutch via a friction clutch, which is frequently operated with the same pedal as the transmission clutch. This, combined with an engaging mechanism, enables the drive to the power take-off to be stopped and started independently of the drive to the wheels. As a result, the driven machine may continue to operate.Even if the tractor and machine are not moving, you can still operate and process the crop. This is a very convenient configuration and a significant advantage over older tractors with a single clutch, particularly ground driven machines.

Regardless of travel speed, PTO speed is determined by engine speed (with a fixed ratio of 3 or 4:1). (traction transmission ratio). The power losses in the PTO drive are typically less than 5\%.A "ground-speed" PTO can also be installed (Fig. 1.1). The drive to the PTO shaft is linked to the drive to the wheels after the traction transmission, so the PTO speed changes as the traction transmission ratio changes. The ground speed PTO rotates slowly (a few revolutions per unit distance travelled) and can be used in place of a ground drive on machines such as seed drills where a fixed relationship between tractor movement and machine function is required.

The two engaging mechanisms for the PTO drive are designed in such a way that only one of them can be used at the same time.

\section{(c) Hydraulic (oil) supply}

Here, oil under pressure from a hydraulic pump, which is continuously driven by the engine, is available to operate linear actuators (cylinders, rams), which are typically used to control (raise and lower) implements or to drive rotating actuators (motors). A ram like this is built into the tractor and is used to raise the three-point linkage.

Power losses in the hydraulic system may be moderate, but they are tolerated because this outlet is a versatile and convenient method of controlling machines and operating auxiliaries on the tractor and attached machines.

\section{ENGINE SPECIFICATIONS}

a. Make/Model: Kirloskar Oil Engines Ltd. (KOEL)/ CC418

b. Type: Single Cylinder, Diesel, 418CC, Vertical,

c. Rating: 8 hp@3000 rpm

d. Max Torque: 19N.m@2000 rpm

e. High Idle: $3300 \mathrm{rpm}$

f. Dry weight: $44 \mathrm{~kg}$

g. Size: 470x310x490 cm

h. Fuel tank capacity: $3.5 \mathrm{~L}$

i. Starting method: Rope Start 


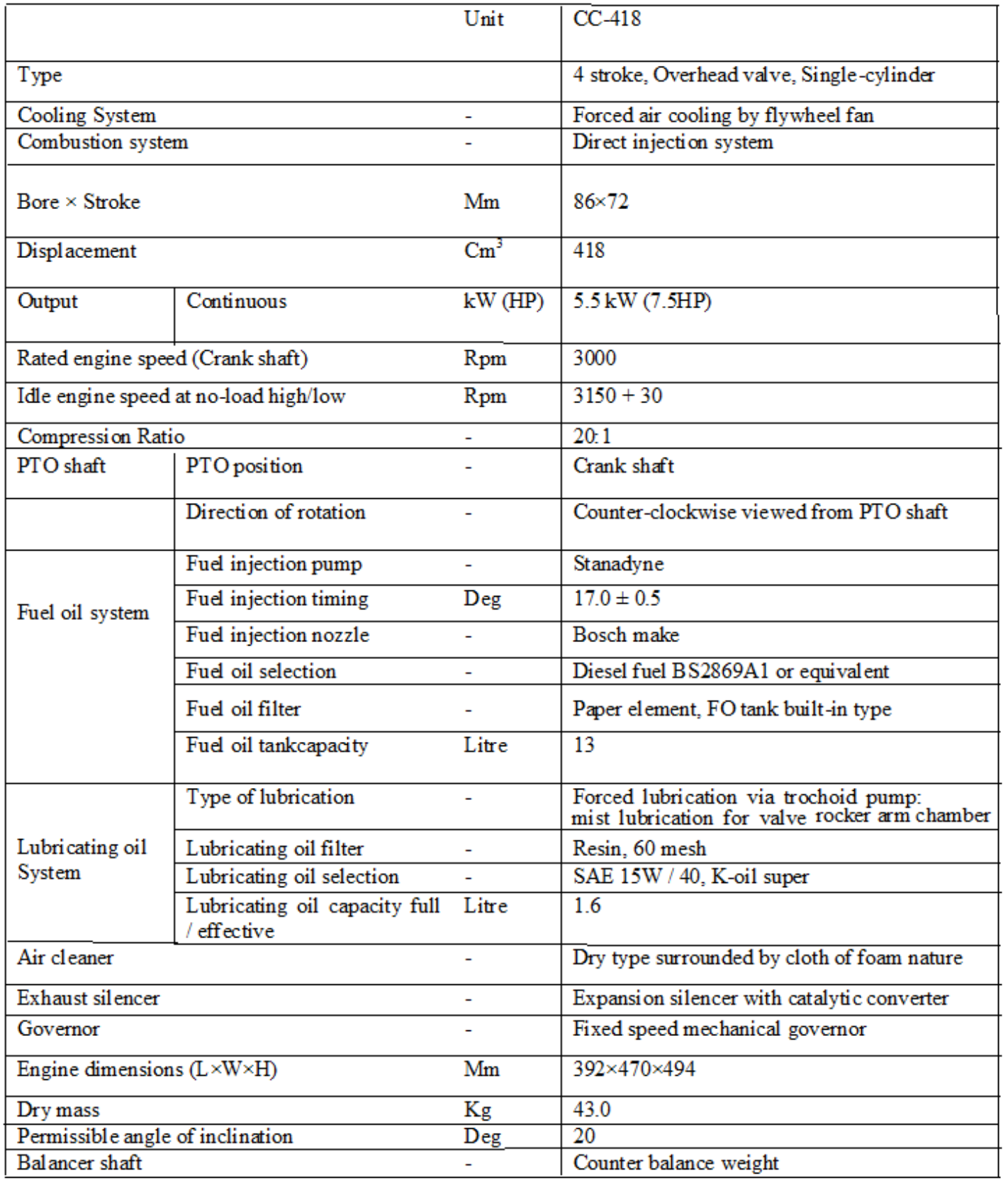




\section{CALCULATIONS}

\subsection{Speed}

The following generally applies for the calculation of the driving speed on the basis of engine speed, tyre size and overall ratio: Speed

$$
\mathrm{V}=\frac{0.06 \times \mathrm{N}_{\mathrm{MOT}} \times \mathrm{U}}{\mathrm{I}_{\mathrm{G}} \times \mathrm{I}_{\mathrm{V}} \times \mathrm{I}_{\mathrm{A}}}
$$

Where:

$\mathrm{V}=$ Driving speed, in $\mathrm{km} / \mathrm{h}$

$\mathrm{N}_{\text {MOT }}=$ Engine speed, in $1 / \mathrm{min}$

$\mathrm{U}=$ Tyre rolling circumference, in $\mathrm{m}$

$\mathrm{I}_{\mathrm{G}}=$ Transmission ratio

$\mathrm{I}_{\mathrm{v}}=$ Transfer case ratio

$\mathrm{I}_{\mathrm{A}}=$ Final drive ratio of the driven axle(s)

\subsection{Tractive force}

The tractive force is dependent on:

- Engine torque

- Overall ratio (including that of the wheels)

- Efficiency of power transmission

Tractive force

$\mathrm{F}_{\mathrm{Z}}=\left(2 \times \pi \times \mathrm{M}_{\operatorname{mot}} \times \mathrm{n} \times \mathrm{I}_{\mathrm{G}} \times \mathrm{I}_{\mathrm{x}} \times \mathrm{I}_{\mathrm{A}}\right) / \mathrm{U}$

$\mathrm{F}_{Z}=$ Tractive force, in $\mathrm{N}$

$\mathrm{M}_{\mathrm{Mot}}=$ Engine torque, in $\mathrm{Nm}$

$\eta=$ Overall efficiency in the drive train

$\mathrm{I}_{\mathrm{G}}=$ Transmission ratio

$\mathrm{I}_{\mathrm{v}}=$ Transfer case ratio

$I_{A}=$ Final drive ratio of the driven axle(s)

$\mathrm{U}=$ Tyre rolling circumference, in $\mathrm{m}$

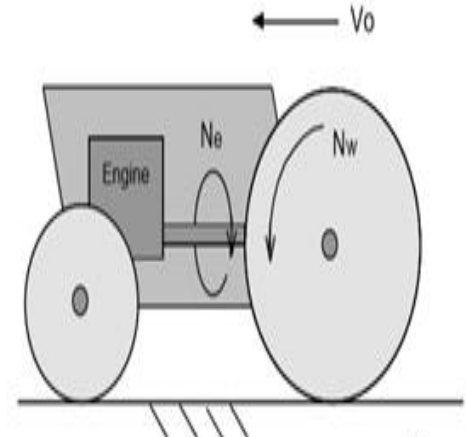

(a)

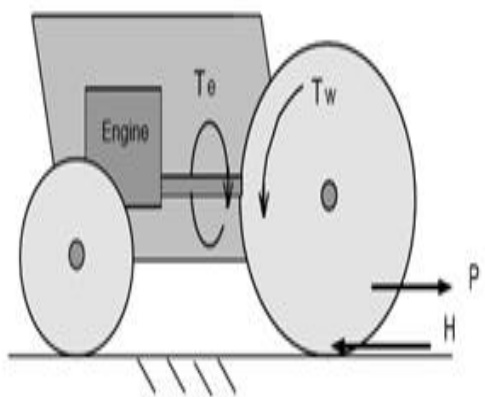

(b)

Figure 4: - Mechanics of the tractor under ideal conditions (a) Speed analysis;

(b) Torque / force analysis

\subsection{Gradeability}

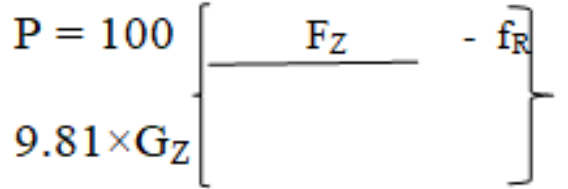

Where: -

$\mathrm{P}=$ Gradeability, in \%

$\mathrm{F}_{z}=$ Tractive force in $\mathrm{N}$

$\mathrm{G}_{\mathrm{Z}}=$ Overall combined mass, in $\mathrm{kg}$ $\mathrm{f}_{\mathrm{R}}=$ Coefficient of rolling resistance 
Table 1: - Coefficients of rolling resistance

\begin{tabular}{|c|c|}
\hline Road surface & ${\text { Coefficient } \mathrm{f}_{\mathrm{R}}}$ \\
\hline Good asphalt road & 0.007 \\
\hline Wet asphalt road & 0.015 \\
\hline Good concrete road & 0.008 \\
\hline Rough concrete road & 0.011 \\
\hline Block paving & 0.017 \\
\hline Poor road & 0.032 \\
\hline Dirt track & $0.15-0.94$ \\
\hline Loose sand & $0.15-0.30$ \\
\hline
\end{tabular}

Table 2: - Overall efficiency in the drive train

\begin{tabular}{|c|c|}
\hline $\begin{array}{c}\text { Number of driven } \\
\text { axles }\end{array}$ & $\boldsymbol{\eta}$ \\
\hline One driven axle & 0.95 \\
\hline Two driven axles & 0.9 \\
Three driven axles & 0.85 \\
\hline
\end{tabular}

\subsection{Travel Speed calculations}

Gearbox Used: - Constant Mesh Gearbox (Piaggio Ape)

Type ofClutch: - Multiplate Clutch

Type of reduction gear box used: -Helical reduction gearbox

Table 3: - Travel speed calculations

\begin{tabular}{|c|c|c|c|c|c|}
\hline Gear & $\begin{array}{c}\text { Transmission } \\
\text { Gear Ratio }\end{array}$ & $\begin{array}{c}\text { Differential } \\
\text { Gear Ratio }\end{array}$ & $\begin{array}{c}\text { Reduction } \\
\text { Gear Ratio }\end{array}$ & $\begin{array}{c}\text { Vehicle Speed in } \\
\text { KMIPH at 2000 } \\
\text { RPMI }\end{array}$ & $\begin{array}{c}\text { Vehicle Speed in } \\
\text { KIPH at3000 } \\
\text { RPMI }\end{array}$ \\
\hline $1^{\text {st }}$ & 4.6 & 2.38 & 10 & 2.622 & 3.934 \\
\hline $2^{\text {nd }}$ & 2.733 & 2.38 & 10 & 4.414 & 6.622 \\
\hline $3^{\text {rd }}$ & 1.667 & 2.38 & 10 & 7.237 & 10.856 \\
\hline $4^{\text {th }}$ & 1.115 & 2.38 & 10 & 10.821 & 14.875 \\
\hline Revers & 4.6 & 4.17 & 10 & 1.497 & 2.245 \\
\hline e & & & & & \\
\hline
\end{tabular}

\subsection{Layout of Transmission System}

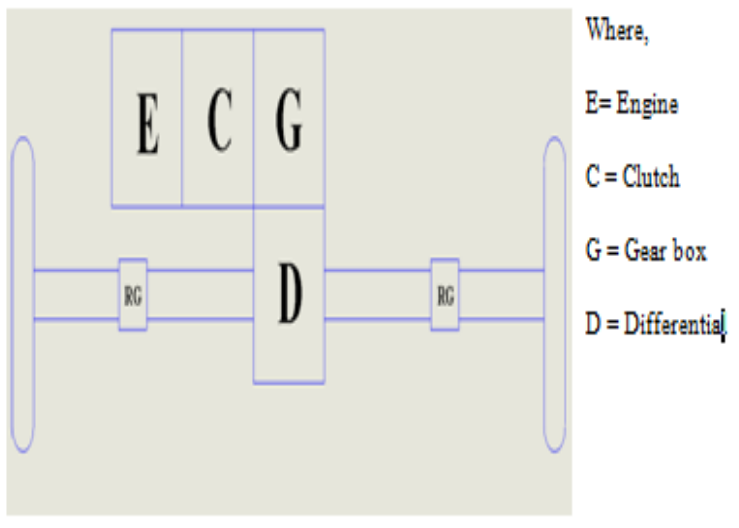

$\mathrm{RG}=$ Reduction Gearbox 


\section{TYRES}

Various types of wheels and / or tyres may be used on the vehicle, depending mainly on the surface on which it is working.

\subsection{Drive tyres:}

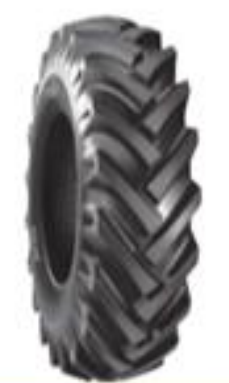

\section{AS 504}

AS 504 is an agro-industrial tire mainly designed for transport and soil tillage operations. In some sizes, AS 504 is suitable for loading and hay harvesting applications. This tire, which features excellent self-cleaning properties and increased grip, is ideal for muddy grounds. There are several versions of the AS 504 tire to meet specific end-user requirements.

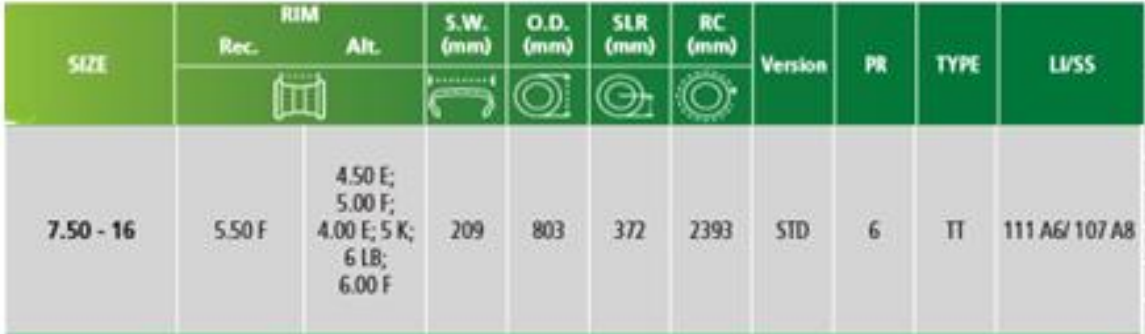

\begin{tabular}{|c|c|c|}
\hline & CAPAC & \\
\hline $\mathrm{km} / \mathrm{h}$ & 2.30 & 3.00 \\
\hline 30 FR LIV & 900 & - \\
\hline 30 DW LV & 630 & . \\
\hline 30 FR HLV & . & 1090 \\
\hline 40 FR HIV & . & 975 \\
\hline
\end{tabular}

6.2. Front tyres:
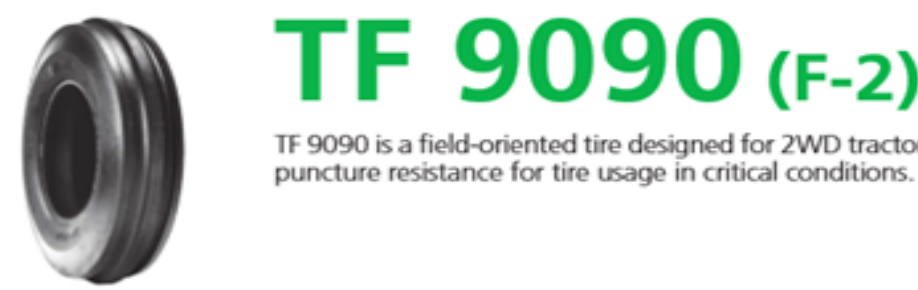

TF 9090 is a field-oriented tire designed for 2WD tractors in soil tillage operations. Its "special" version ensures extra puncture resistance for tire usage in critical conditions.

\begin{tabular}{|c|c|c|c|c|c|c|c|c|c|c|c|c|}
\hline \multirow{3}{*}{ SILE } & \multicolumn{2}{|c|}{$\mathrm{RIM}$} & \multirow{2}{*}{$\begin{array}{l}\text { S.W. } \\
(\mathrm{mm})\end{array}$} & \multirow{2}{*}{$\begin{array}{l}\text { O.D. } \\
(\mathrm{mm})\end{array}$} & \multirow{2}{*}{$\underset{(m m)}{\text { SLR }}$} & \multirow{2}{*}{$\underset{(\mathrm{mm})}{\mathrm{RC}}$} & \multirow{3}{*}{ Version } & \multirow{3}{*}{$\mathrm{PR}$} & \multirow{3}{*}{ TYRE } & \multirow{3}{*}{ wss } & \multicolumn{2}{|c|}{ LOAD CAPACITY $30 \mathrm{KM} / \mathrm{H}$} \\
\hline & Rec. & Alt & & & & & & & & & & \\
\hline & & & 52 & 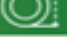 & (H) & $(0)$ & & & & & bar & $\max$ load (kg) \\
\hline $5.00-15$ & $4.00 \mathrm{E}$ & $\begin{array}{c}3.00 \mathrm{D} ; 4 \mathrm{t} \\
4 \mathrm{KJ}\end{array}$ & 140 & 655 & 307 & 1951 & SID & 6 & II & $82 \mathrm{A6}$ & 3.70 & 475 \\
\hline
\end{tabular}

\section{FUTURE SCOPE}

1. Extensive work on transmission system for implementation of different types of attachment systems like cleaning, sorting of onion bulbs.

2. Improved design of transmission system to achieve different operable conditions (i.e. conditions according to different soil conditions, weather, crops).

3. Improvisation of design to achieve full atomization in harvesting process of onion crop.

\section{CONCLUSION}

In this report, transmission system for selfpropelled onion harvester is designed by using constant mesh gearbox with integrated differential and additional helical reduction gearbox is used to achieve appropriate operation speed of harvester on onion field.

\section{REFERENCES}

1. Bekker, M.G. (1956) The theory of land locomotion - the mechanics of vehicle mobility. (University of Michigan Press). 
2. Goodwin, A.B. (1979) Fluid Power Systems - theory, worked examples and problems (Macmillan).

3. Liljedahl, J.B., Turnquist, P.J., Smith, D.W. and Hoki, M. (1989): Tractors and their power units. 4th Edition (Van Nostrand), Chapter 1.

4. Reece, A.R. (1965-66): Principles of soil-vehicle mechanics. Proceedings of Institution of Mechanical Engineers, Vol. $180,(2 \mathrm{~A})$

5. Reece, A.R. (1967) Tractor design and tractive performance. Institution of Agricultural Engineers, Agricultural Engineering Symposium, Paper No 3/4/E/34, Silsoe, England. 9pp.

6. Vasey, G.H. (1957-8) Hydraulic torque converters in tractors. Proceedings of Automobile Division, Institution of Mechanical Engineers, (4) 103- 117.

7. Wismer, R.D. and Luth, H.J. (1974) Offroad traction prediction for wheeled vehicles. Transactions of American Society of Agricultural Engineers, 17(1) $8-10,14$

8. Brown, W.T. and Baillie, W.F. (1973) Australian Tractor Test Report No 78, Leyland 253. Australian Tractor Testing Committee, University of Melbourne.

9. Society of Automotive Engineers. Vehicle dynamics terminology. In SAE J670e, Warrendale, PA, 1978.

10. M.G.Bekker. Introduction to TerrainVehicle Systems. The University of MichiganPress, Ann Arbor, 1969.

11. B. J. Chan. Development of an off-road capable tire model for vehicle dynamics simulations. $\mathrm{PhD}$ thesis, Virginia Polytechnic Institute and State University, Blacksburg, VA,2008.

12. H. Schwanghart. Lateral forces on steered tyres in loose soil. Journal of Terramechanics, 1968.

13. Transmission of SAE Baja,Naveen Kumar\& Nikhil Verma, IJIRST International Journal for Innovative Research in Science \& Technology| Volume 4 | Issue 5 | October 2017 ISSN (online): 2349-6010

14. Agricultural tires technical data book, BKT tyres. 